\title{
Searching for Rare Type Associations in Bacterial Communities from Ancient Copper Mining Areas in The East Harz Region (Germany)
}

\author{
J Michael Köhler*, Franziska Kalensee, P Mike Günther and Jialan Cao \\ Department of Physics, Germany \\ *Corresponding author: J Michael Köhler, Department of Physics, Germany
}

Submission: 韭 October 05, 2018; Published: 海 December 19, 2018

\begin{abstract}
Surface material from 17 ancient copper mines (15th to beginning $19^{\text {th }}$ century) of the Southeast Harz region (Germany) had been investigated by 16S-RNA NGS profilings. It was found that the places are marked by different quantities of dominant soil bacterial phyla as Proteobacteria, Actinobacteria, Acidobacteria and Verrucomicrobia and by the rarely appearing types (Operational Taxonomical Units OTUs, mostly genus level), which had been found in single samples or in sample groups, exclusively. Some of them could be assigned to sample-related associations, what supports the assumption of a special character and a long-term "genetic memory" of bacteria communities on the ancient mining places.
\end{abstract}

Keywords: Microbial diversity; Soil; Historical mines; Microorganism signatures

\section{Introduction}

Mining areas and other heavy metal-contaminated places are frequently in the focus of investigations on soil microbial communities $[1,2]$. On the one hand, these soil microbiomes are very important for the remediation of destroyed vegetation and for the de-toxification of the heavily contaminated areas $[3,4]$. On the other hand, microorganisms which tolerate extreme environmental conditions are frequently found in these communities, among them acidophilic, halophilic and heavy metal-tolerant bacteria [57]. Finally, the particular conditions in the mining areas promote the development of species and groups with special adaptation on substrate availability and the extraordinary competition situation $[8,9]$. Thus, it could be expected that microorganism with special metabolic features $[10,11]$ are present in such contaminated areas, among them bacteria with special mechanisms for metal ion transport [12] for accumulation of metals [3,13] and for the synthesis of bio-dyes, special enzymes, fungicide substances and antibiotics [14]. Metal-accumulating activities are not only usable for the remediation of contaminated areas, but also of interest for the exploitation of metals from low-concentrated resources, from electronic junk and technical wastes [15]. Fungicide substances and antibiotics are urgently required for human medicine, because physicians are confronted with an increasing distribution of resistance genes and multi-resistant microorganisms. Beside these important aspects, there will develop a large spectrum of new demands for microorganism-based production and material conversion for the transition to a complete sustainable economy.

In general, active or recently closed industrial and mining areas are mainly under investigation and monitoring for their soil conditions and the existing soil microorganisms. But beside them, there was found that prehistoric sites [16,17] and older historical mining and metal processing areas are also marked by special compositions of soil microbial communities [18]. It has to be taken in to account, that the development of microbial strains in such areas and the interaction with plants, macro and micro fauna had much more time for selection and adaptation, for cooperative developments [19] and for the exchange of genes, for example by horizontal gene transfer [20]. An intensive transfer of microorganisms by birds and other animals could have taken place over the centuries and millennia in case of mining areas from historical, antique or prehistoric places. In addition, higher numbers of changes in local conditions could have stimulated the development of special local communities: changing of temperature and humidity during a lot of summers and winters, as well as changing $\mathrm{pH}$ and salinity causing numerable changes in the deliberation and precipitation of metal ions.

Here, soil bacterial communities from 17 historical copper mining places of the Southeast Harz mountain region in central Germany have been investigated by 16S-RNA (ngs) profiling. The mines had been used between the $15^{\text {th }}$ and the $19^{\text {th }}$ century. Soil samples of the region are under investigation for search for heavy metal-tolerant bacterial strains and their characterization by new microfluidic methods supplying highly-resolved dose/ response functions [21,22]. It is to assume that the existence of bacterial strains with special tolerance features is dependent on the local chemical conditions and geological situation as well as on the interaction with other microorganisms. The aim of this study 
was to compare the composition of the microbial communities on the recent surface of historical mining places and search for associations of soil bacteria.

\section{Experimental}

\section{Soil samples}

All samples were directly taken from the surface material of the ancient small ring heaps in the direct neighbourhood of the old shafts. These surface areas were not directly covered by vegetation.
The sample origin is described in Table 1 \& Figure 1 . The earliest messages on copper mining activities speak for a starting of mining near Hettstedt around the year 1200 [23]. The mining near Rodishain dates back to the $15^{\text {th }}$ century. The copper mining near Uftrungen and Breitungen was most intensive in the $18^{\text {th }}$ century, particular between 1715 and 1774 . The majority of the numerous small mines near Hettstedt, Welfesholz, Wiederstedt, Wolferode and Hergisdorf is originating at latest from the end of $18^{\text {th }}$ and the beginning of the $19^{\text {th }}$ century [23].

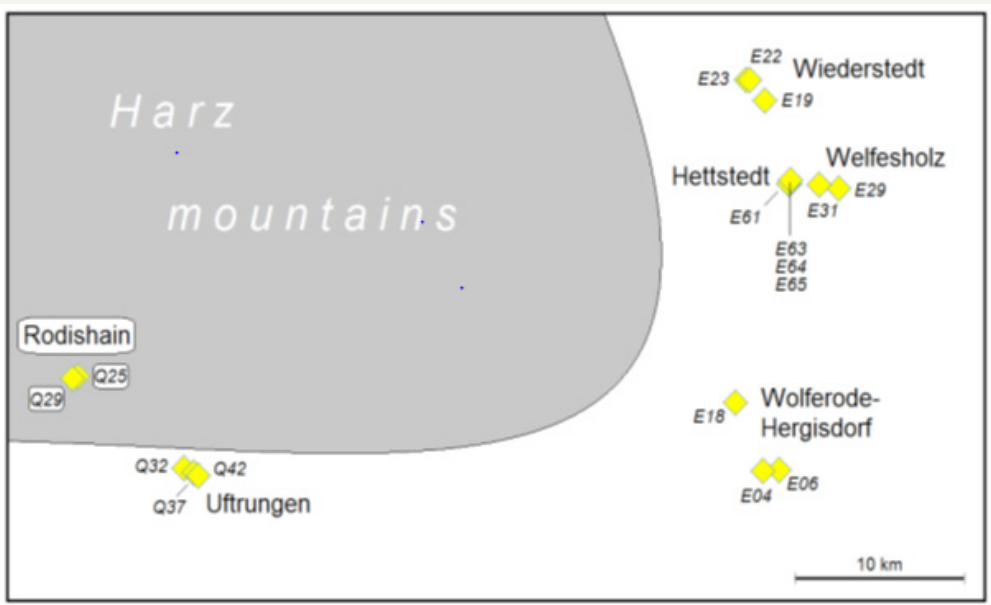

Figure 1: Origin of soil samples: historical mining areas in the Southeast Harz region.

Table 1: Soil samples and related Coordinates (Gauß-Krüger).

\begin{tabular}{|c|c|c|c|}
\hline Mining Area & GK (East) & GK (North) & $5,407,692$ \\
\hline E04 & Wolferode & $4,465,662$ & $5,707,686$ \\
\hline E06 & Wolferode & $4,463,996$ & $5,711,089$ \\
\hline E18 & Hergisdorf & $4,465,778$ & $5,726,125$ \\
\hline E19 & Wiederstedt & $4,464,656$ & $5,727,151$ \\
\hline E22 & Wiederstedt & $4,464,895$ & $5,727,149$ \\
\hline E23 & Wiederstedt & $4,470,244$ & $5,721,753$ \\
\hline E29 & Welfesholz & $5,469,068$ & $5,721,957$ \\
\hline E31 & Welfesholz & $4,467,222$ & $5,721,981$ \\
\hline E61 & Hettstedt & $4,467,258$ & $5,722,002$ \\
\hline E63 & Hettstedt & $4,467,256$ & $5,722,008$ \\
\hline E64 & Hettstedt & 4467,32 & $5,722,189$ \\
\hline E65 & Hettstedt & $4,424,444$ & $5,712,399$ \\
\hline Q25 & Rodishain & 4424,16 & 5712,28 \\
\hline Q29 & Rodishain & 4430,82 & $5,707,821$ \\
\hline Q32 & Uftrungen & $4,431,432$ & $5,707,589$ \\
\hline Q37 & Uftrungen & $4,431,725$ & $5,707,443$ \\
\hline
\end{tabular}

\section{DNA extraction and data processing}

DNA was extracted from the samples by a Power Soil Isolation Kit (MO BIO, Carlsbad, USA) according to the manufactor's protocol. An Edvocycler (Edvotek, Washington D.C.) was applied for PCRs. Each PCR amplification step was verified by gel electrophoresis. Therefore, $1.2 \%$ agarose gels were applied. Single PCR products as well as pooled DNA libraries were purified with AMPure XP beads (Beckman Coulter, Brea, USA).

For Amplicon PCR adaptor primers A519F-Ad5'TCGTCGGCAGCGTCAGATGTGTATAAGAGACAGCAGCMGCCGCGGTAA 3') and Bact_805R-Ad (5'-GTCTCGT GGGCTCGGAGATGTGTATAAGAGACAGGACTACHVGGGTATCTAATC 3') were used $(100 \mathrm{pmol} / \mu \mathrm{l})$, which were 
obtained from Eurofins Genomics (Ebersberg, Germany). The reaction mixtures with a total volume of $50 \mu \mathrm{l}$ per reaction contained $1 \mu \mathrm{l}$ of DNA Isolation eluate, $2 \mathrm{mM} \mathrm{MgCl} 2,200 \mu \mathrm{M}$ PCR nucleotide mix, 1,25 Units GoTaq G2 Flexi DNA Polymerase, nuclease free water (all reagents from Promega, Madison (USA)) and $1 \mu \mathrm{mol} / \mathrm{l}$ of each primer. Amplicon PCR program settings were as follows: $94{ }^{\circ} \mathrm{C}$ for $5 \mathrm{~min}, 30$ cycles of denaturation at $94{ }^{\circ} \mathrm{C}$ for $30 \mathrm{~s}$; annealing at $50{ }^{\circ} \mathrm{C}$ for $30 \mathrm{~s}$; extension at $72{ }^{\circ} \mathrm{C}$ for $30 \mathrm{~s}$; and a final extension at $72{ }^{\circ} \mathrm{C}$ for $5 \mathrm{~min})$.

A519F-Ad5'TCGTCGGCAGCGTCAGATGTGTATAAGAGACAGCA GCMGCCGCGGTAA 3') and Bact_805R-Ad(5'-GTCTCGTGGGCTCG GAGATGTGTATAAGAGACAGGACTACHVGGGTATCTAATC 3') were used $(100 \mathrm{pmol} / \mu \mathrm{l})$, which were obtained from Eurofins Genomics (Ebersberg, Germany). The reaction mixtures with a total volume of $50 \mu \mathrm{l}$ per reaction contained $1 \mu \mathrm{l}$ of DNA Isolation eluate, $2 \mathrm{mM}$ MgCl2, 200 $\mu \mathrm{M}$ PCR nucleotide mix, 1,25 Units GoTaq G2 Flexi DNA Polymerase, nuclease free water (all reagents from Promega, Madison (USA)) and $1 \mu \mathrm{mol} / \mathrm{l}$ of each primer. Amplicon PCR program settings were as follows: $94{ }^{\circ} \mathrm{C}$ for $5 \mathrm{~min}, 30$ cycles of denaturation at $94^{\circ} \mathrm{C}$ for 30 s; annealing at $50^{\circ} \mathrm{C}$ for 30 s; extension at $72{ }^{\circ} \mathrm{C}$ for 30 $\mathrm{s}$; and a final extension at $72{ }^{\circ} \mathrm{C}$ for $5 \mathrm{~min}$ ).

The automatic software pipeline of the SILVAngs data analysis service [24-26] was used for the community analysis of the NGS data. All data files from GATC Biotech first had to be converted from fastq file format to fasta file format, because the fastq file format was not compatible to upload. The used fastq-to-fasta converter software was "phred33 conversion" from MR DNA Lab. All data sets were analysed using the preset parameters of the settings page and with the SILVAngs database release version 128 [25].

In many cases, the sequences allowed to assign bacterial groups down to the genus level. In other cases, the identification with higher taxonomical levels could be achieved, only. The lowest identified level was always referenced as "Operational Taxonomic
Unit" (OTU) for the comparison of bacterial diversity and for the calculation of the Shannon index.

There are several methods for measuring the diversity of microbiomes by DNA profilings. Here, the Shannon index H was chosen for characterization due to its representation of the whole spectra of OTUs including the fraction of rare types [27].

$$
\mathrm{H}=-\Sigma \mathrm{p}_{\mathrm{i}} \star \ln \left(\mathrm{p}_{\mathrm{i}}\right)
$$

where $\mathrm{p}_{\mathrm{i}}$ represents the ratio of the number of detected single sequences of each OUT $\mathrm{N}_{\mathrm{i}}$ to the total number of OTUs $\mathrm{N}_{0}$ :

$$
\mathrm{p}_{i}=\mathrm{N}_{i} / \mathrm{N}_{0}(2)
$$

\section{Results and Discussion}

\section{Comparison of dominant phyla}

The overwhelming majority of identified sequences of all 17 soil samples is represented by eleven phyla. In general, the phyla composition is varying moderately between the different areas and samples (Figure 2). Proteobacteria and Actinobacteria are dominating in the most samples. In one case (Q32) Verrucomicrobia is the dominating phylum. Bacteriodetes, Acidobacteria, Gemmatimonadetes, Planctomyctes and Chloroflexi are also strongly represented, Nitrospirae, Cyanobacteria and Firmicutes are less frequent. An analysis of a large set of bacterial species records showed that the three phyla Proteobacteria, Actinobacteria and Bacteriodetes, but in addition Firmicutes are most frequent, in general [28]. Instead of Actinobacteria, Acidobacteria are identified to belong to the most important four phyla beside Proteobacteria, Bacteriodetes and Firmicutes in soil samples from derelicted mining sites [29]. This corresponds largely to the observation, that the bacterial communities between un-contaminated environments and mining areas are not clearly distinguishable at the phylum level [30].

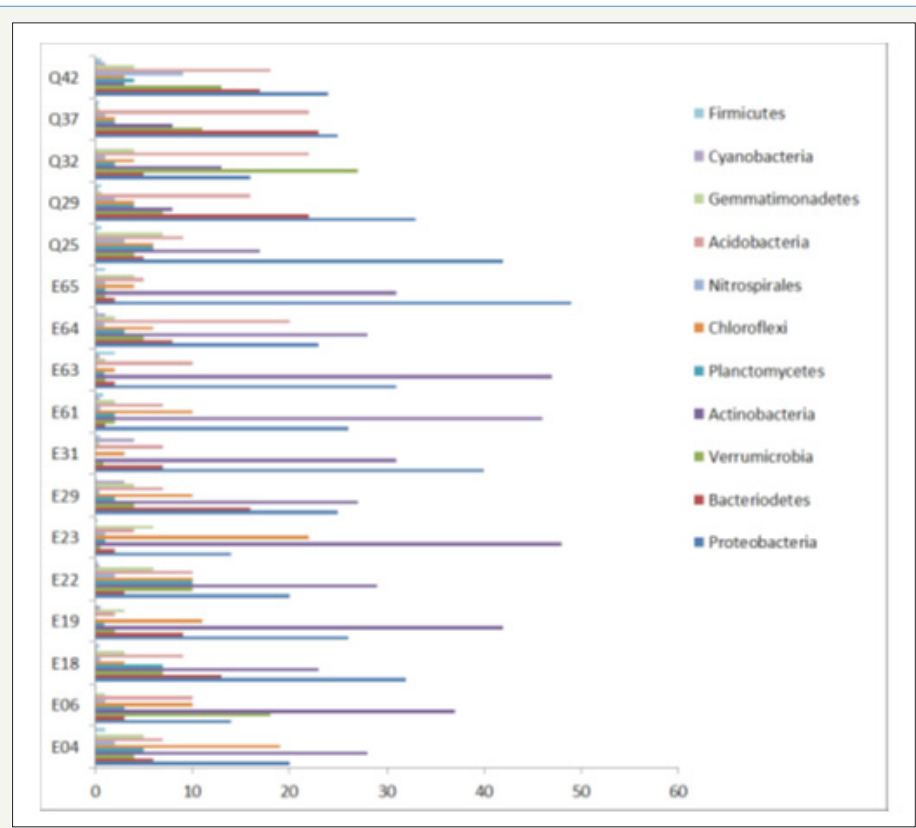

Figure 2: Frequency of the 11 most prominent phyla on the investigated places. 
A comparison of the normalized frequencies of the single phyla in all communities shows that these 11 phyla can be subdivided in three groups with different correlation behaviour in the soil compositions: At first, the plots (Figure 3) of the first three principle components of the Principle Component Analysis (PCA) reflect a group of six phyla with similar positions (triangles in Figure 3). In this group Planctomycetes and Gemmatimonadetes are associated, on the one hand, Chloroflexi, Actinobacteria and Firmicutes, on the other hand. Proteobacteria are more related to the second group in the both first plots (Figure 3) and more to Planctomycetes and Gemmatimonadetes in the third plot (Figure 3). Further, there is observed another pair of associated phyla (Bacteriodetes and Acidobacteria, shown by the crosses in the PCA plots). The other three phyla (Nitrospirae, Cyanobacteria and Verrucomicrobia) are much less related to the above-mentioned association groups and to each other.

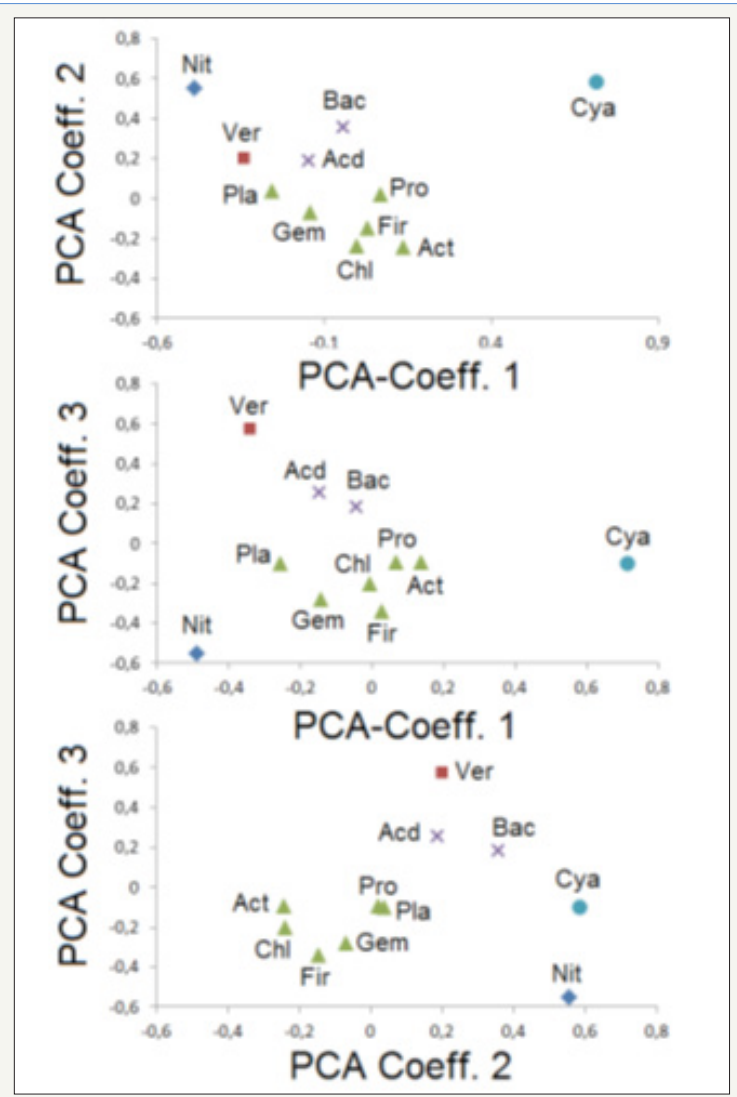

Figure 3: Principle Component Analysis (PCA, correlations between the first three principle components) for the normalized frequency distribution of the most prominent phyla: Acd: Acidobacteria; Act: Actinobacteria; Bac: Bacteriodetes; Chl: Chloroflexi; Cya: Cyanobacteria; Fir: Firmicutes; Gem: Gemmatimonadetes; Nit: Nitrospirae; Pla: Planctomycetes; Pro: Proteobacteria; Ver: Verrucomicrobia

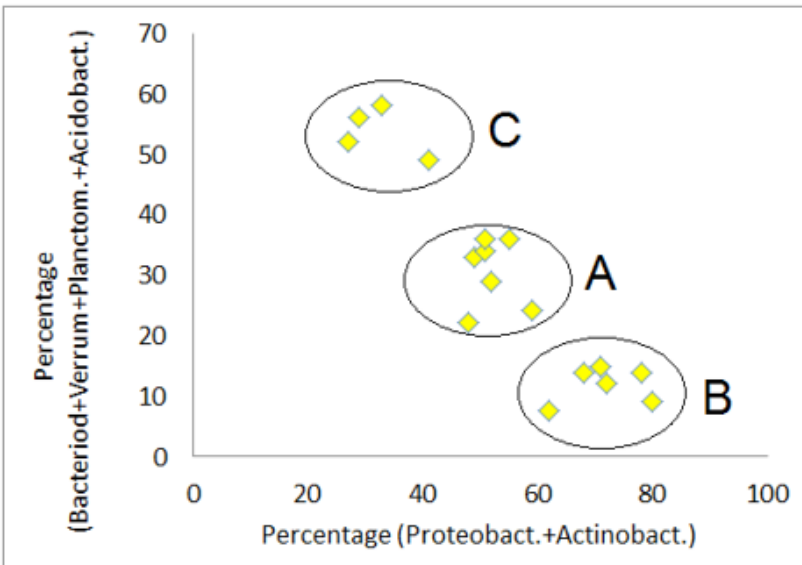

Figure 4: Correlation of the total of the phyla group "Acidobacteria-Bacteriodetes-Planctomycetes-Verrucomicrobia" and the phyla group "Proteobacteria-Actinobacteria". 
Proteobacteria and Actinobacteria are the most prominent phyla. A comparison of the total of their both frequencies with the total of the other four particular frequent phyla (Bacteriodetes, Verrucomicrobia, Planctomycetes and Acidobacteria) leads to the expected negative correlation (Figure 4). But, the correlation plot shows, that the soil samples are forming three different clusters. The four samples of cluster B (Q29, Q32, Q37 and Q42) belong exclusively to the both most western mining areas of Rodishain and Uftrungen. The group character of $A$ and $B$ (high and mediate percentage of Proteobacteria and/or Actinobacteria) is underlined by the different levels of the negative correlation between this both phyla (Figure 5). A significant difference of groups C and B is reflected by the Verrucomicrobia content (Figure 5). In group C, there is not only the evidence of high Verrucomicrobia content, but it is also decreasing with increasing Shannon index of the whole set of OTUs, which is a measure for the genetic diversity of the sample. In contrast, the members of group B show an increase of Verrucomicrobia with increasing Shannon index.

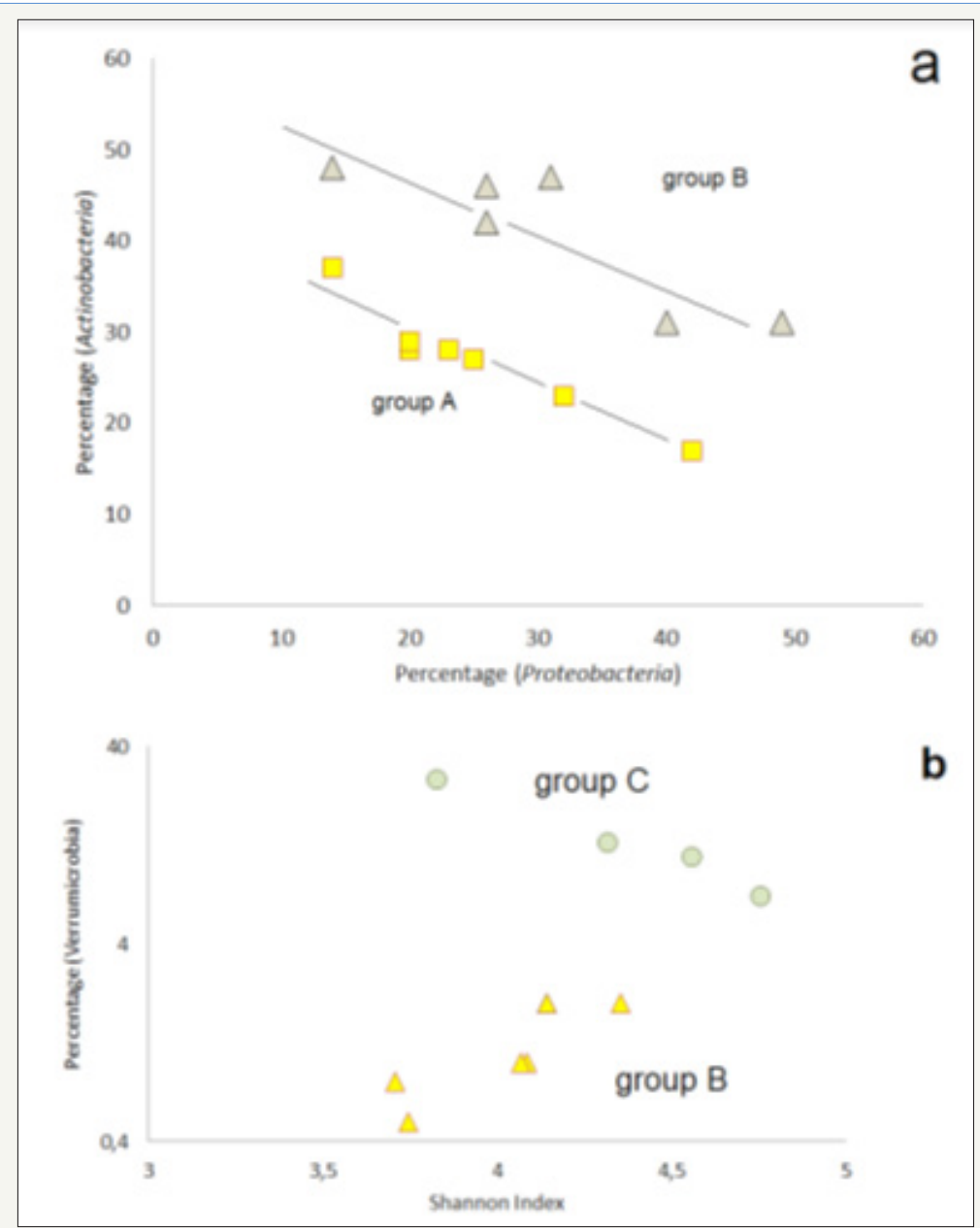

Figure 5: Correlations in the three sample groups A, B, and C: a) correlation between the frequency of Actinobacteria and Proteobacteria in the community groups A (squares) and B (triangles), b) correlation of the percentage of Verrucomicrobia sequences in dependence on the Shannon index of the related bacterial communities' triangles: group B, circles: group C.

The both correlations suggest that the increasing Verrucomicrobia content indicates an increase in diversity at a lower Verrucomicrobia level, but a decrease in diversity at a higher content level. A certain correlation of the Shannon index was also found for some frequently appearing single OTUs. Thus, it was observed, that the DA101 soil group (Verrucomicrobia) is negatively correlated with Shannon index, what corresponds to the negative correlation of the sample group C.

\section{Representation of special operational taxonomical units (OTUs)}

The majority of sequences of the most prominent phyla is represented by a comparatively small set of OTUs. The nine most frequent OTUs have been compared by a separate PCA for all 17 soil samples (Figure 6). The first three Principle Components reflect a group of four narrowly coupled OTUs (triangles in Figure 6). These are the groups KD4-96 (Chloroflexi), Sphingomonas (Proteobacteria), Gaiella (Actinobacteria) and an uncultivatedmarked group of Acidomicrobia (Actinobacteria). A certain association is also given by two groups of Acidobacteria, namely RB41 and Subgroup6 (crosses in Figure 6). Three further groups (DA101, Ralstonia and Gailellales uncult. group) show no relation with each other and with the other groups. Sphingomonas is known as a taxon from heavy metal-contaminated soils [31]. It is as well as Gaillela [32] and Ralstonia Xie et al. [33] reported from metal mines, too Feng et al. [34]. 


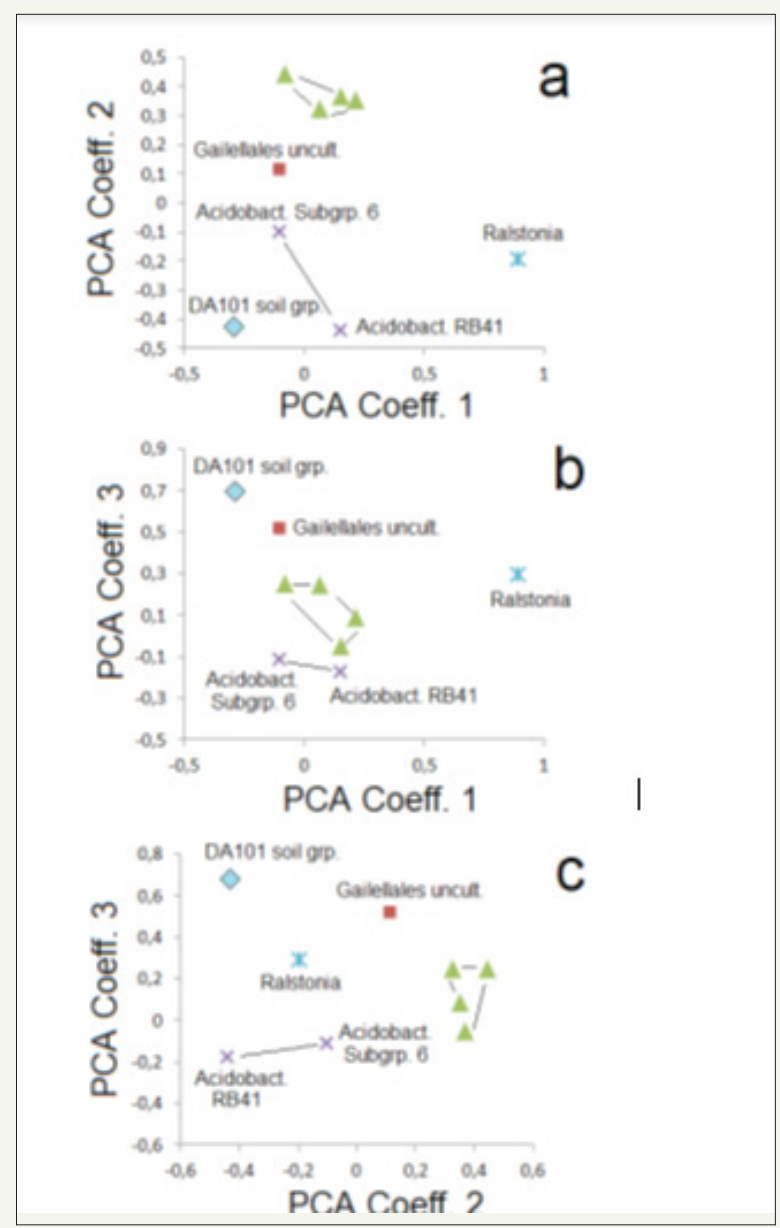

Figure 6: PCA (first three principle components) for the nine most prominent operational taxonomical units (OTUs): triangles: KD4-96 (Chloroflexi), Gaiella (Actinobacteria), Sphingomonas (Proteobacteria) and Acidimicrobia, uncultivated group (Actinobacteria))

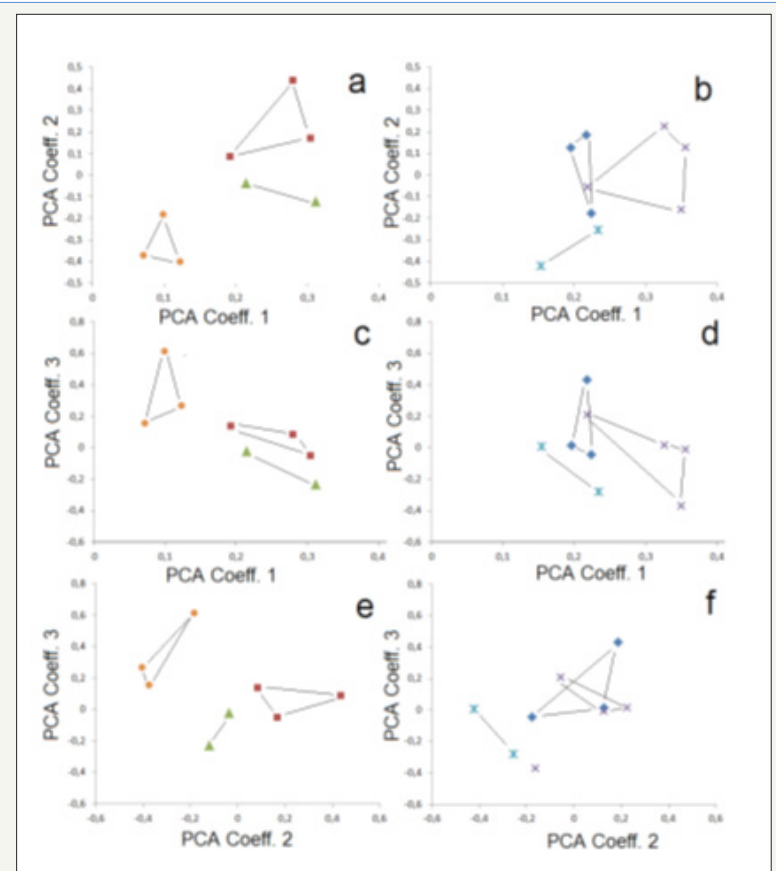

Figure 7: PCA of soil community groups for the six different mining locations: a,b) components 1 and 2, c, d: components 1 and 3, e, f: components 2 and 3; a, c, d: squares:region Wiederstedt (E19, E22, E23), triangles: region Welfesholz (E29, E31), circles: region Uftrungen (Q32, Q37, Q42); b.d.f: diamonds: region Wolferode-Hergisdorf (E04, E06, E18), crosses: region Hettstedt (E61, E63, E64, E65), stars: region Rodishain (Q25-Q29). 
PCA plots have also been applied for analysing relations between the investigated mining areas. The first three Principle Components indicate clearly similarities in the samples from the Uftrungen area (Q32, Q37, Q42), from the Wiederstedt area (E19, E22, E23) and from the Welfesholz area (E31, E29). The plots in Figure 7 show that these sample groups can be distinguished from each other. The samples from the other three areas are less clear related and cannot be clear distinguished from the other samples (Figure 7).

The 16S-RNA profiling supplied a mean OTU number per sample of about 550 (Table 2, supplementary material). The lowest number of OTUs (300) came from sample E19, the highest (906) from sample Q29. The Shannon index ranges between 3.71 (sample E31, 406 OTUs) and 5.25 (sample E18, 522 OTUs) with a mean value of 4.35. The Shannon indices of sample E19 (4.14) and Q29 (4.76) are in the mean range. Obviously, there is no correlation between the observed number of OTUs and the Shannon Indices. This relation is changed if the OTUs are regarded which have been found exclusively in one of the samples, but in no other sample. Sample Q29 had the absolute highest number (91) of exclusively found OTUs, what means that about $10 \%$ of OTUs are exclusive. The portion of exclusive OTUs differs between 1.6\% (E22) and 10\%, what means that it is much more diverse than the Shannon index and the absolute OTU number. From all samples, a total of 457 OTUs had been identified, which were contained exclusively in one of the samples. These are $27 \%$ of the 1705 OTUs, which were found in all samples in total. The majority of the exclusively found OTUs are on the genus level. A complete overview of exclusively to one sample assigned OTUs represented by three or more sequences are shown in Table 3 (supplementary material). The high number indicates the high probability to found rare types on the Genus level in a comparatively small set of samples from the ancient mining areas.

Table 2: Shannon indices and percentages of exclusively found OTUs.

\begin{tabular}{|c|c|c|c|c|}
\hline $\mathbf{a}$ & b & c & d & $\mathbf{e}$ \\
\hline Soil & Shannon & & OTUs & \\
\hline Sample & Index & OTUs ges & (Exclusv) & $\%$ Excl OTUs \\
\hline E04 & 4,65 & 528 & 34 & 6,4 \\
\hline E06 & 4,08 & 664 & 30 & 4,5 \\
\hline E18 & 5,25 & 522 & 23 & 4,4 \\
\hline E19 & 4,14 & 300 & 13 & 4,3 \\
\hline E22 & 4,25 & 367 & 6 & 1,6 \\
\hline E23 & 3,74 & 472 & 16 & 3,4 \\
\hline E29 & 4,62 & 467 & 13 & 2,8 \\
\hline E31 & 3,71 & 406 & 9 & 2,2 \\
\hline E61 & 4,35 & 383 & 16 & 4,2 \\
\hline E63 & 4,09 & 545 & 29 & 5,3 \\
\hline E64 & 4,68 & 683 & 33 & 4,8 \\
\hline E65 & 4,07 & 548 & 22 & 4,0 \\
\hline Q25 & 4,80 & 608 & 27 & 4,4 \\
\hline Q29 & 4,76 & 906 & 91 & 10,0 \\
\hline Q32 & 3,83 & 487 & 30 & 6,2 \\
\hline Q37 & 4,56 & 808 & 47 & 5,8 \\
\hline Q42 & 4,31 & 656 & 18 & 2,7 \\
\hline Mean & 4,35 & 550 & 27 & 4,55 \\
\hline
\end{tabular}

a) Sample number.

b) Shannon index $\mathrm{H}$ of reconsidering all OTUs of each sample.

c) Total number of assigned OTUs of each sample.

d) Number of OTUs exclusively found in the related sample.

e) Percentage of exclusively found OTUs.

Table 3: Exclusively in one sample assigned OTUs (represented by 3 or more sequences).

\begin{tabular}{|c|c|c|c|c|c|c|c|c|c|c|c|c|c|c|c|c|c|c|c|}
\hline $\begin{array}{c}\text { Phylum } \\
\text { (Stamm) }\end{array}$ & $\begin{array}{c}\text { Family } \\
\text { (Familie) }\end{array}$ & $\begin{array}{c}\text { Genus } \\
\text { (Gattung) }\end{array}$ & E04 & E06 & E18 & E19 & E22 & E23 & E29 & E31 & E61 & E63 & E64 & E65 & Q25 & Q29 & Q32 & Q37 & Q42 \\
\hline $\begin{array}{c}\text { Proteo- } \\
\text { bacteria }\end{array}$ & Nautiliaceae & $\begin{array}{c}\text { Camini- } \\
\text { bacter }\end{array}$ & 3 & 0 & 0 & 0 & 0 & 0 & 0 & 0 & 0 & 0 & 0 & 0 & 0 & 0 & 0 & 0 & 0 \\
\hline
\end{tabular}




\begin{tabular}{|c|c|c|c|c|c|c|c|c|c|c|c|c|c|c|c|c|c|c|c|}
\hline $\begin{array}{l}\text { Firmic- } \\
\text { utes }\end{array}$ & $\begin{array}{l}\text { Peptostrepto- } \\
\text { coccaceae }\end{array}$ & $\begin{array}{l}\text { Rombout- } \\
\text { sia }\end{array}$ & 3 & 0 & 0 & 0 & 0 & 0 & 0 & 0 & 0 & 0 & 0 & 0 & 0 & 0 & 0 & 0 & 0 \\
\hline $\begin{array}{l}\text { Actino- } \\
\text { bacteria }\end{array}$ & $\begin{array}{l}\text { Micrococca- } \\
\text { ceae }\end{array}$ & $\begin{array}{l}\text { Paeniglu- } \\
\text { tamici- } \\
\text { bacter }\end{array}$ & 4 & 0 & 0 & 0 & 0 & 0 & 0 & 0 & 0 & 0 & 0 & 0 & 0 & 0 & 0 & 0 & 0 \\
\hline $\begin{array}{l}\text { Proteo- } \\
\text { bacteria }\end{array}$ & $\begin{array}{c}\text { Sphingo- } \\
\text { monadaceae }\end{array}$ & $\begin{array}{l}\text { Sandaraci- } \\
\text { nobacter }\end{array}$ & 0 & 3 & 0 & 0 & 0 & 0 & 0 & 0 & 0 & 0 & 0 & 0 & 0 & 0 & 0 & 0 & 0 \\
\hline $\begin{array}{l}\text { Proteo- } \\
\text { bacteria }\end{array}$ & $\begin{array}{l}\text { Enterobacte- } \\
\text { riaceae }\end{array}$ & Kluyvera & 0 & 3 & 0 & 0 & 0 & 0 & 0 & 0 & 0 & 0 & 0 & 0 & 0 & 0 & 0 & 0 & 0 \\
\hline $\begin{array}{l}\text { Deinococ- } \\
\text { cus-Ther- } \\
\quad \text { mus }\end{array}$ & Thermaceae & $\begin{array}{l}\text { Meiother- } \\
\text { mus }\end{array}$ & 0 & 5 & 0 & 0 & 0 & 0 & 0 & 0 & 0 & 0 & 0 & 0 & 0 & 0 & 0 & 0 & 0 \\
\hline $\begin{array}{l}\text { Proteo- } \\
\text { bacteria }\end{array}$ & Nautiliaceae & $\begin{array}{l}\text { Lebeti- } \\
\text { monas }\end{array}$ & 0 & 0 & 3 & 0 & 0 & 0 & 0 & 0 & 0 & 0 & 0 & 0 & 0 & 0 & 0 & 0 & 0 \\
\hline $\begin{array}{l}\text { Proteo- } \\
\text { bacteria }\end{array}$ & $\begin{array}{l}\text { Archangia- } \\
\text { ceae }\end{array}$ & $\begin{array}{l}\text { Melittan- } \\
\text { gium }\end{array}$ & 0 & 0 & 4 & 0 & 0 & 0 & 0 & 0 & 0 & 0 & 0 & 0 & 0 & 0 & 0 & 0 & 0 \\
\hline $\begin{array}{l}\text { Proteo- } \\
\text { bacteria }\end{array}$ & $\begin{array}{l}\text { Enterobacte- } \\
\text { riaceae }\end{array}$ & Proteus & 0 & 0 & 5 & 0 & 0 & 0 & 0 & 0 & 0 & 0 & 0 & 0 & 0 & 0 & 0 & 0 & 0 \\
\hline $\begin{array}{l}\text { Proteo- } \\
\text { bacteria }\end{array}$ & $\begin{array}{l}\text { Phyllobacte- } \\
\text { riaceae }\end{array}$ & & 0 & 0 & 5 & 0 & 0 & 0 & 0 & 0 & 0 & 0 & 0 & 0 & 0 & 0 & 0 & 0 & 0 \\
\hline $\begin{array}{l}\text { Proteo- } \\
\text { bacteria }\end{array}$ & Rhizobiaceae & $\begin{array}{l}\text { Neorhizo- } \\
\text { bium }\end{array}$ & 0 & 0 & 7 & 0 & 0 & 0 & 0 & 0 & 0 & 0 & 0 & 0 & 0 & 0 & 0 & 0 & 0 \\
\hline $\begin{array}{l}\text { Bacteroi- } \\
\text { detes }\end{array}$ & $\begin{array}{l}\text { Cytophaga- } \\
\text { ceae }\end{array}$ & Larkinella & 0 & 0 & 7 & 0 & 0 & 0 & 0 & 0 & 0 & 0 & 0 & 0 & 0 & 0 & 0 & 0 & 0 \\
\hline $\begin{array}{l}\text { Proteo- } \\
\text { bacteria }\end{array}$ & $\begin{array}{l}\text { Hyphomicro- } \\
\text { biaceae }\end{array}$ & & 0 & 0 & 7 & 0 & 0 & 0 & 0 & 0 & 0 & 0 & 0 & 0 & 0 & 0 & 0 & 0 & 0 \\
\hline $\begin{array}{l}\text { Proteo- } \\
\text { bacteria }\end{array}$ & $\begin{array}{l}\text { Hydrogeno- } \\
\text { philaceae }\end{array}$ & $\begin{array}{c}\text { Sul- } \\
\text { furiferula }\end{array}$ & 0 & 0 & 7 & 0 & 0 & 0 & 0 & 0 & 0 & 0 & 0 & 0 & 0 & 0 & 0 & 0 & 0 \\
\hline $\begin{array}{l}\text { Proteo- } \\
\text { bacteria }\end{array}$ & $\begin{array}{l}\text { Archangia- } \\
\text { ceae }\end{array}$ & $\begin{array}{l}\text { Cystob- } \\
\text { acter }\end{array}$ & 0 & 0 & 10 & 0 & 0 & 0 & 0 & 0 & 0 & 0 & 0 & 0 & 0 & 0 & 0 & 0 & 0 \\
\hline $\begin{array}{l}\text { Chlorof- } \\
\text { lexi }\end{array}$ & $\begin{array}{l}\text { Kallotenua- } \\
\text { ceae }\end{array}$ & Kallotenue & 0 & 0 & 0 & 3 & 0 & 0 & 0 & 0 & 0 & 0 & 0 & 0 & 0 & 0 & 0 & 0 & 0 \\
\hline $\begin{array}{l}\text { Bacteroi- } \\
\text { detes }\end{array}$ & $\begin{array}{l}\text { Sphingobac- } \\
\text { teriaceae }\end{array}$ & Olivibacter & 0 & 0 & 0 & 3 & 0 & 0 & 0 & 0 & 0 & 0 & 0 & 0 & 0 & 0 & 0 & 0 & 0 \\
\hline $\begin{array}{l}\text { Bacteroi- } \\
\text { detes }\end{array}$ & $\begin{array}{c}\text { Chitino- } \\
\text { phagaceae }\end{array}$ & $\begin{array}{l}\text { Vibrioni- } \\
\text { monas }\end{array}$ & 0 & 0 & 0 & 5 & 0 & 0 & 0 & 0 & 0 & 0 & 0 & 0 & 0 & 0 & 0 & 0 & 0 \\
\hline $\begin{array}{l}\text { Firmic- } \\
\text { utes }\end{array}$ & $\begin{array}{l}\text { Halobacte- } \\
\text { roidaceae }\end{array}$ & $\begin{array}{l}\text { Natroniel- } \\
\quad l a\end{array}$ & 0 & 0 & 0 & 6 & 0 & 0 & 0 & 0 & 0 & 0 & 0 & 0 & 0 & 0 & 0 & 0 & 0 \\
\hline $\begin{array}{l}\text { Proteo- } \\
\text { bacteria }\end{array}$ & $\begin{array}{l}\text { Erythrobac- } \\
\text { teraceae }\end{array}$ & $\begin{array}{l}\text { Croceicoc- } \\
\quad \text { cus }\end{array}$ & 0 & 0 & 0 & 0 & 0 & 3 & 0 & 0 & 0 & 0 & 0 & 0 & 0 & 0 & 0 & 0 & 0 \\
\hline $\begin{array}{l}\text { Firmic- } \\
\text { utes }\end{array}$ & $\begin{array}{l}\text { Ruminococ- } \\
\text { caceae }\end{array}$ & $\begin{array}{c}\text { Rumino- } \\
\text { coccaceae } \\
\text { UCG-011 }\end{array}$ & 0 & 0 & 0 & 0 & 0 & 3 & 0 & 0 & 0 & 0 & 0 & 0 & 0 & 0 & 0 & 0 & 0 \\
\hline $\begin{array}{l}\text { Actino- } \\
\text { bacteria }\end{array}$ & $\begin{array}{l}\text { Micromono- } \\
\text { sporaceae }\end{array}$ & $\begin{array}{c}\text { Phyto- } \\
\text { monospora }\end{array}$ & 0 & 0 & 0 & 0 & 0 & 3 & 0 & 0 & 0 & 0 & 0 & 0 & 0 & 0 & 0 & 0 & 0 \\
\hline $\begin{array}{l}\text { Proteo- } \\
\text { bacteria }\end{array}$ & $\begin{array}{l}\text { Bartonella- } \\
\quad \text { ceae }\end{array}$ & Bartonella & 0 & 0 & 0 & 0 & 0 & 9 & 0 & 0 & 0 & 0 & 0 & 0 & 0 & 0 & 0 & 0 & 0 \\
\hline $\begin{array}{l}\text { Actino- } \\
\text { bacteria }\end{array}$ & $\begin{array}{l}\text { Glycomyceta- } \\
\text { ceae }\end{array}$ & $\begin{array}{l}\text { Glycomy- } \\
\text { ces }\end{array}$ & 0 & 0 & 0 & 0 & 0 & 9 & 0 & 0 & 0 & 0 & 0 & 0 & 0 & 0 & 0 & 0 & 0 \\
\hline $\begin{array}{l}\text { Firmic- } \\
\text { utes }\end{array}$ & $\begin{array}{l}\text { Peptostrepto- } \\
\text { coccaceae }\end{array}$ & $\begin{array}{l}\text { Terrispo- } \\
\text { robacter }\end{array}$ & 0 & 0 & 0 & 0 & 0 & 13 & 0 & 0 & 0 & 0 & 0 & 0 & 0 & 0 & 0 & 0 & 0 \\
\hline $\begin{array}{l}\text { Firmic- } \\
\text { utes }\end{array}$ & $\begin{array}{l}\text { Carnobacte- } \\
\text { riaceae }\end{array}$ & $\begin{array}{l}\text { Carnobac- } \\
\text { terium }\end{array}$ & 0 & 0 & 0 & 0 & 0 & 0 & 3 & 0 & 0 & 0 & 0 & 0 & 0 & 0 & 0 & 0 & 0 \\
\hline $\begin{array}{l}\text { Proteo- } \\
\text { bacteria }\end{array}$ & $\begin{array}{l}\text { Methylobac- } \\
\text { teriaceae }\end{array}$ & & 0 & 0 & 0 & 0 & 0 & 0 & 3 & 0 & 0 & 0 & 0 & 0 & 0 & 0 & 0 & 0 & 0 \\
\hline $\begin{array}{l}\text { Firmic- } \\
\text { utes }\end{array}$ & $\begin{array}{l}\text { Peptococca- } \\
\text { ceae }\end{array}$ & $\begin{array}{l}\text { Thermin- } \\
\text { cola }\end{array}$ & 0 & 0 & 0 & 0 & 0 & 0 & 3 & 0 & 0 & 0 & 0 & 0 & 0 & 0 & 0 & 0 & 0 \\
\hline
\end{tabular}




\begin{tabular}{|c|c|c|c|c|c|c|c|c|c|c|c|c|c|c|c|c|c|c|c|}
\hline $\begin{array}{c}\text { Cyano- } \\
\text { bacteria }\end{array}$ & & & 0 & 0 & 0 & 0 & 0 & 0 & 4 & 0 & 0 & 0 & 0 & 0 & 0 & 0 & 0 & 0 & 0 \\
\hline $\begin{array}{l}\text { Bacteroi- } \\
\text { detes }\end{array}$ & $\begin{array}{l}\text { Bacteroida- } \\
\text { ceae }\end{array}$ & $\begin{array}{l}\text { Bacteroi- } \\
\text { des }\end{array}$ & 0 & 0 & 0 & 0 & 0 & 0 & 0 & 3 & 0 & 0 & 0 & 0 & 0 & 0 & 0 & 0 & 0 \\
\hline $\begin{array}{l}\text { Chlorof- } \\
\text { lexi }\end{array}$ & $\begin{array}{c}\text { Anaerolin- } \\
\text { eaceae }\end{array}$ & $\begin{array}{l}\text { Anaero- } \\
\text { linea }\end{array}$ & 0 & 0 & 0 & 0 & 0 & 0 & 0 & 17 & 0 & 0 & 0 & 0 & 0 & 0 & 0 & 0 & 0 \\
\hline $\begin{array}{l}\text { Tectomi- } \\
\text { crobia }\end{array}$ & $\begin{array}{l}\text { Unknown } \\
\text { Family }\end{array}$ & $\begin{array}{l}\text { Candidatus } \\
\text { Entothe- } \\
\text { onella }\end{array}$ & 0 & 0 & 0 & 0 & 0 & 0 & 0 & 0 & 3 & 0 & 0 & 0 & 0 & 0 & 0 & 0 & 0 \\
\hline $\begin{array}{l}\text { Firmic- } \\
\text { utes }\end{array}$ & $\begin{array}{l}\text { Clostridiace- } \\
\quad \text { ae } 1\end{array}$ & $\begin{array}{l}\text { Clostridi- } \\
\text { um sensu } \\
\text { str. } 10\end{array}$ & 0 & 0 & 0 & 0 & 0 & 0 & 0 & 0 & 5 & 0 & 0 & 0 & 0 & 0 & 0 & 0 & 0 \\
\hline $\begin{array}{l}\text { Firmic- } \\
\text { utes }\end{array}$ & $\begin{array}{l}\text { Sporolacto- } \\
\text { bacillaceae }\end{array}$ & $\begin{array}{l}\text { Sporolac- } \\
\text { tobacillus }\end{array}$ & 0 & 0 & 0 & 0 & 0 & 0 & 0 & 0 & 5 & 0 & 0 & 0 & 0 & 0 & 0 & 0 & 0 \\
\hline $\begin{array}{l}\text { Actino- } \\
\text { bacteria }\end{array}$ & $\begin{array}{l}\text { Micrococca- } \\
\text { ceae }\end{array}$ & $\begin{array}{l}\text { Zhihengli- } \\
\text { uella }\end{array}$ & 0 & 0 & 0 & 0 & 0 & 0 & 0 & 0 & 9 & 0 & 0 & 0 & 0 & 0 & 0 & 0 & 0 \\
\hline $\begin{array}{c}\text { Proteo- } \\
\text { bacteria }\end{array}$ & $\begin{array}{l}\text { Moraxella- } \\
\text { ceae }\end{array}$ & $\begin{array}{l}\text { Enhydro- } \\
\text { bacter }\end{array}$ & 0 & 0 & 0 & 0 & 0 & 0 & 0 & 0 & 17 & 0 & 0 & 0 & 0 & 0 & 0 & 0 & 0 \\
\hline $\begin{array}{l}\text { Proteo- } \\
\text { bacteria }\end{array}$ & $\begin{array}{l}\text { Burkholderi- } \\
\text { aceae }\end{array}$ & $\begin{array}{l}\text { uncul- } \\
\text { tured }\end{array}$ & 0 & 0 & 0 & 0 & 0 & 0 & 0 & 0 & 43 & 0 & 0 & 0 & 0 & 0 & 0 & 0 & 0 \\
\hline $\begin{array}{l}\text { Elusimi- } \\
\text { crobia }\end{array}$ & $\begin{array}{l}\text { Elusimicrobi- } \\
\text { aceae }\end{array}$ & $\begin{array}{l}\text { Elusimi- } \\
\text { crobium }\end{array}$ & 0 & 0 & 0 & 0 & 0 & 0 & 0 & 0 & 0 & 3 & 0 & 0 & 0 & 0 & 0 & 0 & 0 \\
\hline $\begin{array}{l}\text { Proteo- } \\
\text { bacteria }\end{array}$ & $\begin{array}{c}\text { Oxalobacter- } \\
\text { aceae }\end{array}$ & $\begin{array}{l}\text { Pseudodu- } \\
\text { ganella }\end{array}$ & 0 & 0 & 0 & 0 & 0 & 0 & 0 & 0 & 0 & 3 & 0 & 0 & 0 & 0 & 0 & 0 & 0 \\
\hline $\begin{array}{l}\text { Firmic- } \\
\text { utes }\end{array}$ & $\begin{array}{l}\text { Aerococca- } \\
\text { ceae }\end{array}$ & Aerococcus & 0 & 0 & 0 & 0 & 0 & 0 & 0 & 0 & 0 & 3 & 0 & 0 & 0 & 0 & 0 & 0 & 0 \\
\hline $\begin{array}{l}\text { Proteo- } \\
\text { bacteria }\end{array}$ & $\begin{array}{l}\text { Chromatia- } \\
\text { ceae }\end{array}$ & $\begin{array}{c}\text { Rhein- } \\
\text { heimera }\end{array}$ & 0 & 0 & 0 & 0 & 0 & 0 & 0 & 0 & 0 & 4 & 0 & 0 & 0 & 0 & 0 & 0 & 0 \\
\hline $\begin{array}{l}\text { Proteo- } \\
\text { bacteria }\end{array}$ & АСОС1ВВ07 & & 0 & 0 & 0 & 0 & 0 & 0 & 0 & 0 & 0 & 5 & 0 & 0 & 0 & 0 & 0 & 0 & 0 \\
\hline $\begin{array}{l}\text { Actino- } \\
\text { bacteria }\end{array}$ & $\begin{array}{l}\text { Intraspo- } \\
\text { rangiaceae }\end{array}$ & $\begin{array}{l}\text { Ornithin- } \\
\text { imicrobi- } \\
\quad \text { um }\end{array}$ & 0 & 0 & 0 & 0 & 0 & 0 & 0 & 0 & 0 & 6 & 0 & 0 & 0 & 0 & 0 & 0 & 0 \\
\hline $\begin{array}{l}\text { Actino- } \\
\text { bacteria }\end{array}$ & $\begin{array}{l}\text { Microbacte- } \\
\text { riaceae }\end{array}$ & $\begin{array}{l}\text { Gryllotal- } \\
\text { picola }\end{array}$ & 0 & 0 & 0 & 0 & 0 & 0 & 0 & 0 & 0 & 6 & 0 & 0 & 0 & 0 & 0 & 0 & 0 \\
\hline $\begin{array}{l}\text { Firmic- } \\
\text { utes }\end{array}$ & $\begin{array}{l}\text { Peptostrepto- } \\
\text { coccaceae }\end{array}$ & $\begin{array}{l}\text { Peptost- } \\
\text { reptococ- } \\
\quad \text { cus }\end{array}$ & 0 & 0 & 0 & 0 & 0 & 0 & 0 & 0 & 0 & 6 & 0 & 0 & 0 & 0 & 0 & 0 & 0 \\
\hline $\begin{array}{l}\text { Firmic- } \\
\text { utes }\end{array}$ & Family XI & $\begin{array}{c}\text { Mur- } \\
\text { dochiella }\end{array}$ & 0 & 0 & 0 & 0 & 0 & 0 & 0 & 0 & 0 & 11 & 0 & 0 & 0 & 0 & 0 & 0 & 0 \\
\hline $\begin{array}{l}\text { Proteo- } \\
\text { bacteria }\end{array}$ & $\begin{array}{l}\text { Acetobacter- } \\
\text { aceae }\end{array}$ & & 0 & 0 & 0 & 0 & 0 & 0 & 0 & 0 & 0 & 12 & 0 & 0 & 0 & 0 & 0 & 0 & 0 \\
\hline $\begin{array}{l}\text { Proteo- } \\
\text { bacteria }\end{array}$ & $\begin{array}{l}\text { Cellvibriona- } \\
\text { ceae }\end{array}$ & $\begin{array}{c}\text { Maricur- } \\
\text { vus }\end{array}$ & 0 & 0 & 0 & 0 & 0 & 0 & 0 & 0 & 0 & 15 & 0 & 0 & 0 & 0 & 0 & 0 & 0 \\
\hline $\begin{array}{c}\text { Chlorof- } \\
\text { lexi }\end{array}$ & uncultured & & 0 & 0 & 0 & 0 & 0 & 0 & 0 & 0 & 0 & 0 & 3 & 0 & 0 & 0 & 0 & 0 & 0 \\
\hline $\begin{array}{c}\text { Proteo- } \\
\text { bacteria }\end{array}$ & $\begin{array}{c}\text { Rhodospiril- } \\
\text { laceae }\end{array}$ & Tistlia & 0 & 0 & 0 & 0 & 0 & 0 & 0 & 0 & 0 & 0 & 3 & 0 & 0 & 0 & 0 & 0 & 0 \\
\hline $\begin{array}{l}\text { Bacteroi- } \\
\text { detes }\end{array}$ & $\begin{array}{l}\text { Cytophaga- } \\
\text { ceae }\end{array}$ & Rudanella & 0 & 0 & 0 & 0 & 0 & 0 & 0 & 0 & 0 & 0 & 3 & 0 & 0 & 0 & 0 & 0 & 0 \\
\hline $\begin{array}{c}\text { Proteo- } \\
\text { bacteria }\end{array}$ & $\begin{array}{c}\text { Acetobacter- } \\
\text { aceae }\end{array}$ & Stella & 0 & 0 & 0 & 0 & 0 & 0 & 0 & 0 & 0 & 0 & 4 & 0 & 0 & 0 & 0 & 0 & 0 \\
\hline $\begin{array}{c}\text { Cyano- } \\
\text { bacteria }\end{array}$ & & & 0 & 0 & 0 & 0 & 0 & 0 & 0 & 0 & 0 & 0 & 6 & 0 & 0 & 0 & 0 & 0 & 0 \\
\hline $\begin{array}{l}\text { Bacteroi- } \\
\text { detes }\end{array}$ & $\begin{array}{c}\text { Flavobacteri- } \\
\text { aceae }\end{array}$ & $\begin{array}{l}\text { Mohei- } \\
\text { bacter }\end{array}$ & 0 & 0 & 0 & 0 & 0 & 0 & 0 & 0 & 0 & 0 & 6 & 0 & 0 & 0 & 0 & 0 & 0 \\
\hline
\end{tabular}




\begin{tabular}{|c|c|c|c|c|c|c|c|c|c|c|c|c|c|c|c|c|c|c|c|}
\hline $\begin{array}{l}\text { Actino- } \\
\text { bacteria }\end{array}$ & $\begin{array}{l}\text { Streptospo- } \\
\text { rangiaceae }\end{array}$ & $\begin{array}{l}\text { Planotet- } \\
\text { raspora }\end{array}$ & 0 & 0 & 0 & 0 & 0 & 0 & 0 & 0 & 0 & 0 & 7 & 0 & 0 & 0 & 0 & 0 & 0 \\
\hline $\begin{array}{l}\text { Actino- } \\
\text { bacteria }\end{array}$ & $\begin{array}{l}\text { Pseudono- } \\
\text { cardiaceae }\end{array}$ & $\begin{array}{l}\text { Actino- } \\
\text { synnema }\end{array}$ & 0 & 0 & 0 & 0 & 0 & 0 & 0 & 0 & 0 & 0 & 7 & 0 & 0 & 0 & 0 & 0 & 0 \\
\hline $\begin{array}{l}\text { Actino- } \\
\text { bacteria }\end{array}$ & $\begin{array}{l}\text { Promicro- } \\
\text { monospora- } \\
\text { ceae }\end{array}$ & $\begin{array}{l}\text { Myceligen- } \\
\text { erans }\end{array}$ & 0 & 0 & 0 & 0 & 0 & 0 & 0 & 0 & 0 & 0 & 8 & 0 & 0 & 0 & 0 & 0 & 0 \\
\hline $\begin{array}{l}\text { Bacteroi- } \\
\text { detes }\end{array}$ & $\begin{array}{l}\text { Cryomorpha- } \\
\text { ceae }\end{array}$ & $\begin{array}{l}\text { Luteibacu- } \\
\quad \text { lum }\end{array}$ & 0 & 0 & 0 & 0 & 0 & 0 & 0 & 0 & 0 & 0 & 9 & 0 & 0 & 0 & 0 & 0 & 0 \\
\hline $\begin{array}{c}\text { Cyano- } \\
\text { bacteria }\end{array}$ & FamilyI & & 0 & 0 & 0 & 0 & 0 & 0 & 0 & 0 & 0 & 0 & 18 & 0 & 0 & 0 & 0 & 0 & 0 \\
\hline $\begin{array}{l}\text { Actino- } \\
\text { bacteria }\end{array}$ & $\begin{array}{l}\text { Pseudono- } \\
\text { cardiaceae }\end{array}$ & $\begin{array}{l}\text { Saccharo- } \\
\text { monospora }\end{array}$ & 0 & 0 & 0 & 0 & 0 & 0 & 0 & 0 & 0 & 0 & 19 & 0 & 0 & 0 & 0 & 0 & 0 \\
\hline $\begin{array}{l}\text { Proteo- } \\
\text { bacteria }\end{array}$ & $\begin{array}{l}\text { Alcaligena- } \\
\quad \text { ceae }\end{array}$ & Derxia & 0 & 0 & 0 & 0 & 0 & 0 & 0 & 0 & 0 & 0 & 0 & 3 & 0 & 0 & 0 & 0 & 0 \\
\hline $\begin{array}{l}\text { Firmic- } \\
\text { utes }\end{array}$ & $\begin{array}{l}\text { Thermoan- } \\
\text { aerobactera- } \\
\text { ceae }\end{array}$ & $\begin{array}{c}\text { Syntro- } \\
\text { phaceticus }\end{array}$ & 0 & 0 & 0 & 0 & 0 & 0 & 0 & 0 & 0 & 0 & 0 & 3 & 0 & 0 & 0 & 0 & 0 \\
\hline $\begin{array}{l}\text { Actino- } \\
\text { bacteria }\end{array}$ & $\begin{array}{l}\text { Dermacocca- } \\
\text { ceae }\end{array}$ & Kytococcus & 0 & 0 & 0 & 0 & 0 & 0 & 0 & 0 & 0 & 0 & 0 & 4 & 0 & 0 & 0 & 0 & 0 \\
\hline $\begin{array}{l}\text { Firmic- } \\
\text { utes }\end{array}$ & $\begin{array}{l}\text { Thermoacti- } \\
\text { nomyceta- } \\
\text { ceae }\end{array}$ & Planifilum & 0 & 0 & 0 & 0 & 0 & 0 & 0 & 0 & 0 & 0 & 0 & 4 & 0 & 0 & 0 & 0 & 0 \\
\hline $\begin{array}{l}\text { Firmic- } \\
\text { utes }\end{array}$ & Family XI & $\begin{array}{l}\text { Sedimenti- } \\
\quad \text { bacter }\end{array}$ & 0 & 0 & 0 & 0 & 0 & 0 & 0 & 0 & 0 & 0 & 0 & 5 & 0 & 0 & 0 & 0 & 0 \\
\hline $\begin{array}{l}\text { Firmic- } \\
\text { utes }\end{array}$ & $\begin{array}{l}\text { Peptococca- } \\
\text { ceae }\end{array}$ & $\begin{array}{l}\text { Dehalo- } \\
\text { bacter }\end{array}$ & 0 & 0 & 0 & 0 & 0 & 0 & 0 & 0 & 0 & 0 & 0 & 7 & 0 & 0 & 0 & 0 & 0 \\
\hline $\begin{array}{l}\text { Proteo- } \\
\text { bacteria }\end{array}$ & $\begin{array}{l}\text { Thiotricha- } \\
\text { ceae }\end{array}$ & & 0 & 0 & 0 & 0 & 0 & 0 & 0 & 0 & 0 & 0 & 0 & 14 & 0 & 0 & 0 & 0 & 0 \\
\hline $\begin{array}{l}\text { Proteo- } \\
\text { bacteria }\end{array}$ & $\begin{array}{l}\text { Enterobacte- } \\
\quad \text { riaceae }\end{array}$ & $\begin{array}{l}\text { endosym- } \\
\text { bionts8 }\end{array}$ & 0 & 0 & 0 & 0 & 0 & 0 & 0 & 0 & 0 & 0 & 0 & 0 & 3 & 0 & 0 & 0 & 0 \\
\hline $\begin{array}{l}\text { Actino- } \\
\text { bacteria }\end{array}$ & $\begin{array}{l}\text { Microbacte- } \\
\text { riaceae }\end{array}$ & $\begin{array}{l}\text { Zimmer- } \\
\text { mannella }\end{array}$ & 0 & 0 & 0 & 0 & 0 & 0 & 0 & 0 & 0 & 0 & 0 & 0 & 3 & 0 & 0 & 0 & 0 \\
\hline $\begin{array}{l}\text { Chlorof- } \\
\text { lexi }\end{array}$ & & & 0 & 0 & 0 & 0 & 0 & 0 & 0 & 0 & 0 & 0 & 0 & 0 & 3 & 0 & 0 & 0 & 0 \\
\hline $\begin{array}{l}\text { Proteo- } \\
\text { bacteria }\end{array}$ & uncultured & & 0 & 0 & 0 & 0 & 0 & 0 & 0 & 0 & 0 & 0 & 0 & 0 & 4 & 0 & 0 & 0 & 0 \\
\hline $\begin{array}{l}\text { Proteo- } \\
\text { bacteria }\end{array}$ & $\begin{array}{l}\text { Piscirickettsi- } \\
\text { aceae }\end{array}$ & $\begin{array}{l}\text { Methylo- } \\
\text { phaga }\end{array}$ & 0 & 0 & 0 & 0 & 0 & 0 & 0 & 0 & 0 & 0 & 0 & 0 & 4 & 0 & 0 & 0 & 0 \\
\hline $\begin{array}{l}\text { Firmic- } \\
\text { utes }\end{array}$ & $\begin{array}{l}\text { Paenibacilla- } \\
\text { ceae }\end{array}$ & $\begin{array}{l}\text { Saccharib- } \\
\text { acillus }\end{array}$ & 0 & 0 & 0 & 0 & 0 & 0 & 0 & 0 & 0 & 0 & 0 & 0 & 9 & 0 & 0 & 0 & 0 \\
\hline $\begin{array}{l}\text { Proteo- } \\
\text { bacteria }\end{array}$ & $\begin{array}{l}\text { Desulfohalo- } \\
\text { biaceae }\end{array}$ & $\begin{array}{l}\text { Desulfon- } \\
\text { auticus }\end{array}$ & 0 & 0 & 0 & 0 & 0 & 0 & 0 & 0 & 0 & 0 & 0 & 0 & 9 & 0 & 0 & 0 & 0 \\
\hline $\begin{array}{l}\text { Proteo- } \\
\text { bacteria }\end{array}$ & Sva1033 & & 0 & 0 & 0 & 0 & 0 & 0 & 0 & 0 & 0 & 0 & 0 & 0 & 0 & 3 & 0 & 0 & 0 \\
\hline $\begin{array}{l}\text { Bacteroi- } \\
\text { detes }\end{array}$ & ST-12K33 & & 0 & 0 & 0 & 0 & 0 & 0 & 0 & 0 & 0 & 0 & 0 & 0 & 0 & 3 & 0 & 0 & 0 \\
\hline $\begin{array}{l}\text { Bacteroi- } \\
\text { detes }\end{array}$ & $\begin{array}{l}\text { Saprospira- } \\
\text { ceae }\end{array}$ & $\begin{array}{l}\text { Porti- } \\
\text { bacter }\end{array}$ & 0 & 0 & 0 & 0 & 0 & 0 & 0 & 0 & 0 & 0 & 0 & 0 & 0 & 3 & 0 & 0 & 0 \\
\hline $\begin{array}{l}\text { Deferrib- } \\
\text { acteres }\end{array}$ & $\begin{array}{l}\text { Unknown } \\
\text { Family }\end{array}$ & Caldithrix & 0 & 0 & 0 & 0 & 0 & 0 & 0 & 0 & 0 & 0 & 0 & 0 & 0 & 3 & 0 & 0 & 0 \\
\hline $\begin{array}{l}\text { Plancto- } \\
\text { mycetes }\end{array}$ & $\begin{array}{l}\text { Phycisphaer- } \\
\text { aceae }\end{array}$ & $\begin{array}{c}\text { Ura- } \\
\text { nia-1B-19 } \\
\text { marin. sed. } \\
\text { gr. }\end{array}$ & 0 & 0 & 0 & 0 & 0 & 0 & 0 & 0 & 0 & 0 & 0 & 0 & 0 & 3 & 0 & 0 & 0 \\
\hline $\begin{array}{l}\text { Proteo- } \\
\text { bacteria }\end{array}$ & Eel-36e1D6 & & 0 & 0 & 0 & 0 & 0 & 0 & 0 & 0 & 0 & 0 & 0 & 0 & 0 & 4 & 0 & 0 & 0 \\
\hline $\begin{array}{l}\text { Proteo- } \\
\text { bacteria }\end{array}$ & $\begin{array}{l}\text { Syntropha- } \\
\text { ceae }\end{array}$ & $\begin{array}{l}\text { Desulfo- } \\
\text { monile }\end{array}$ & 0 & 0 & 0 & 0 & 0 & 0 & 0 & 0 & 0 & 0 & 0 & 0 & 0 & 5 & 0 & 0 & 0 \\
\hline
\end{tabular}




\begin{tabular}{|c|c|c|c|c|c|c|c|c|c|c|c|c|c|c|c|c|c|c|c|}
\hline $\begin{array}{l}\text { Plancto- } \\
\text { mycetes }\end{array}$ & & & 0 & 0 & 0 & 0 & 0 & 0 & 0 & 0 & 0 & 0 & 0 & 0 & 0 & 5 & 0 & 0 & 0 \\
\hline $\begin{array}{l}\text { Acidobac- } \\
\text { teria }\end{array}$ & Subgroup 21 & & 0 & 0 & 0 & 0 & 0 & 0 & 0 & 0 & 0 & 0 & 0 & 0 & 0 & 6 & 0 & 0 & 0 \\
\hline $\begin{array}{l}\text { Proteo- } \\
\text { bacteria }\end{array}$ & $\begin{array}{l}\text { Polyangia- } \\
\text { ceae }\end{array}$ & & 0 & 0 & 0 & 0 & 0 & 0 & 0 & 0 & 0 & 0 & 0 & 0 & 0 & 7 & 0 & 0 & 0 \\
\hline $\begin{array}{c}\text { Proteo- } \\
\text { bacteria }\end{array}$ & $\begin{array}{l}\text { Desulfobul- } \\
\text { baceae }\end{array}$ & $\begin{array}{c}\text { Desulfo- } \\
\text { capsa }\end{array}$ & 0 & 0 & 0 & 0 & 0 & 0 & 0 & 0 & 0 & 0 & 0 & 0 & 0 & 10 & 0 & 0 & 0 \\
\hline $\begin{array}{l}\text { Firmic- } \\
\text { utes }\end{array}$ & $\begin{array}{l}\text { Veillonella- } \\
\text { ceae }\end{array}$ & $\begin{array}{l}\text { Mitsuo- } \\
\text { kella }\end{array}$ & 0 & 0 & 0 & 0 & 0 & 0 & 0 & 0 & 0 & 0 & 0 & 0 & 0 & 11 & 0 & 0 & 0 \\
\hline Chlorobi & PHOS-HE36 & & 0 & 0 & 0 & 0 & 0 & 0 & 0 & 0 & 0 & 0 & 0 & 0 & 0 & 13 & 0 & 0 & 0 \\
\hline $\begin{array}{l}\text { Actino- } \\
\text { bacteria }\end{array}$ & $\begin{array}{l}\text { Pseudono- } \\
\text { cardiaceae }\end{array}$ & Kutzneria & 0 & 0 & 0 & 0 & 0 & 0 & 0 & 0 & 0 & 0 & 0 & 0 & 0 & 0 & 3 & 0 & 0 \\
\hline $\begin{array}{l}\text { Elusimi- } \\
\text { crobia }\end{array}$ & $4-29$ & & 0 & 0 & 0 & 0 & 0 & 0 & 0 & 0 & 0 & 0 & 0 & 0 & 0 & 0 & 3 & 0 & 0 \\
\hline $\begin{array}{l}\text { Thau- } \\
\text { marchae- } \\
\text { ota }\end{array}$ & & & 0 & 0 & 0 & 0 & 0 & 0 & 0 & 0 & 0 & 0 & 0 & 0 & 0 & 0 & 4 & 0 & 0 \\
\hline $\begin{array}{l}\text { Actino- } \\
\text { bacteria }\end{array}$ & $\begin{array}{l}\text { Microbacte- } \\
\text { riaceae }\end{array}$ & Cryocola & 0 & 0 & 0 & 0 & 0 & 0 & 0 & 0 & 0 & 0 & 0 & 0 & 0 & 0 & 5 & 0 & 0 \\
\hline $\begin{array}{l}\text { Proteo- } \\
\text { bacteria }\end{array}$ & $\begin{array}{l}\text { Roseiarca- } \\
\text { ceae }\end{array}$ & Roseiarcus & 0 & 0 & 0 & 0 & 0 & 0 & 0 & 0 & 0 & 0 & 0 & 0 & 0 & 0 & 5 & 0 & 0 \\
\hline $\begin{array}{l}\text { Nitrospi- } \\
\text { rae }\end{array}$ & FW13 & & 0 & 0 & 0 & 0 & 0 & 0 & 0 & 0 & 0 & 0 & 0 & 0 & 0 & 0 & 6 & 0 & 0 \\
\hline $\begin{array}{l}\text { Actino- } \\
\text { bacteria }\end{array}$ & $\begin{array}{l}\text { Pseudono- } \\
\text { cardiaceae }\end{array}$ & $\begin{array}{l}\text { Tamarici- } \\
\text { habitans }\end{array}$ & 0 & 0 & 0 & 0 & 0 & 0 & 0 & 0 & 0 & 0 & 0 & 0 & 0 & 0 & 8 & 0 & 0 \\
\hline $\begin{array}{c}\text { Chlorof- } \\
\text { lexi }\end{array}$ & JG30-KF-AS9 & & 0 & 0 & 0 & 0 & 0 & 0 & 0 & 0 & 0 & 0 & 0 & 0 & 0 & 0 & 10 & 0 & 0 \\
\hline $\begin{array}{l}\text { Acidobac- } \\
\text { teria }\end{array}$ & $\begin{array}{l}\text { Acidobac- } \\
\text { teriaceae } \\
\text { (Subg.1) }\end{array}$ & $\begin{array}{l}\text { Acidobac- } \\
\text { terium }\end{array}$ & 0 & 0 & 0 & 0 & 0 & 0 & 0 & 0 & 0 & 0 & 0 & 0 & 0 & 0 & 14 & 0 & 0 \\
\hline $\begin{array}{c}\text { Proteo- } \\
\text { bacteria }\end{array}$ & $\begin{array}{c}\text { Elev- } \\
\text { 16S-1546 }\end{array}$ & & 0 & 0 & 0 & 0 & 0 & 0 & 0 & 0 & 0 & 0 & 0 & 0 & 0 & 0 & 0 & 3 & 0 \\
\hline $\begin{array}{l}\text { Firmic- } \\
\text { utes }\end{array}$ & $\begin{array}{l}\text { Ruminococ- } \\
\text { caceae }\end{array}$ & $\begin{array}{l}\text { [Eubact.] } \\
\text { coprostan- } \\
\text { oligen. }\end{array}$ & 0 & 0 & 0 & 0 & 0 & 0 & 0 & 0 & 0 & 0 & 0 & 0 & 0 & 0 & 0 & 3 & 0 \\
\hline $\begin{array}{l}\text { Nitrospi- } \\
\text { rae }\end{array}$ & FTL22 & & 0 & 0 & 0 & 0 & 0 & 0 & 0 & 0 & 0 & 0 & 0 & 0 & 0 & 0 & 0 & 3 & 0 \\
\hline $\begin{array}{c}\text { Proteo- } \\
\text { bacteria }\end{array}$ & & & 0 & 0 & 0 & 0 & 0 & 0 & 0 & 0 & 0 & 0 & 0 & 0 & 0 & 0 & 0 & 6 & 0 \\
\hline $\begin{array}{c}\text { Proteo- } \\
\text { bacteria }\end{array}$ & $\begin{array}{l}\text { Enterobacte- } \\
\text { riaceae }\end{array}$ & Rahnella & 0 & 0 & 0 & 0 & 0 & 0 & 0 & 0 & 0 & 0 & 0 & 0 & 0 & 0 & 0 & 12 & 0 \\
\hline $\begin{array}{l}\text { Plancto- } \\
\text { mycetes }\end{array}$ & & & 0 & 0 & 0 & 0 & 0 & 0 & 0 & 0 & 0 & 0 & 0 & 0 & 0 & 0 & 0 & 0 & 3 \\
\hline
\end{tabular}

\section{Associated rare 0TUs}

Beside the exclusively in one sample observed OTUs, there exist associations of OTUs, which were exclusively observed in a part of soil samples. It is obvious that the majority of involved OTUs are present with more than one sequence in these associations. Some of these sets of OTUs are shown together with the related soil samples in Figure 8. Acidobacteria are present in several of these groups, what is rather typical for mining areas [35]. The pairing of the group "Elev-16S-1158" (Proteobacteria) with the Subgroup 26 (Acidobacteria) was found in five soil samples (E63, E64, Q29, Q37 and Q42). The pairing is observed in four of the five soil samples with five or more sequences, which is speaking for the significance of the combination of both types (Figure 8). The pairing of Subgroup
20 (Acidobacteria) and Georgfuchsia (Proteobacteria) had been found in two samples (Q29, Q42), only (Figure 8b). Georgfuchsia is described as to be able to decompose aromatic compounds [36].

Typical associations can include also more than two members. Such sets of OTUs have been found from the mining area of Rodishain and Uftrungen. The samples Q25, Q29 and Q37 are connected by a combination (Figure 8) of the groups SAR11 clade and Corallococcus (two OTUs of Proteobacteria) and Alterococcus (Verrucomicrobia). The group SAR11 clade is reported to be a wide spread oceanic bacterium. A relation to special aquatic conditions is also obvious for Corallococcus [37,38] and Alterococcus [39]. Four other OTUs (Niabella/Bacteriodetes, Pseudenhygromyxa/Proteobacteria, Group C47/Planctomycetes, Cand. Lainarchaeum/Diapherotrites) had 
been identified from the three samples Q29, Q37 and Q42 (Figure 8). Whereas Niabella was reported from a greenhouse soil [40-42], Pseudenhygromyxa was isolated from an estuarian marsh [43] and Candidatus Iainarchaium from a gold mine [42]. The combination of HSRC138 (Proteobacteria), Demequina (Actinobacteria) with the subgroup 13 of Acidobacteria and non-specified Micrococcales (Actinobacteria) was observed only in Q29 and Q37 (Figure 8). Demequina is also described as a genus originating from tidal flat sediment samples [44].

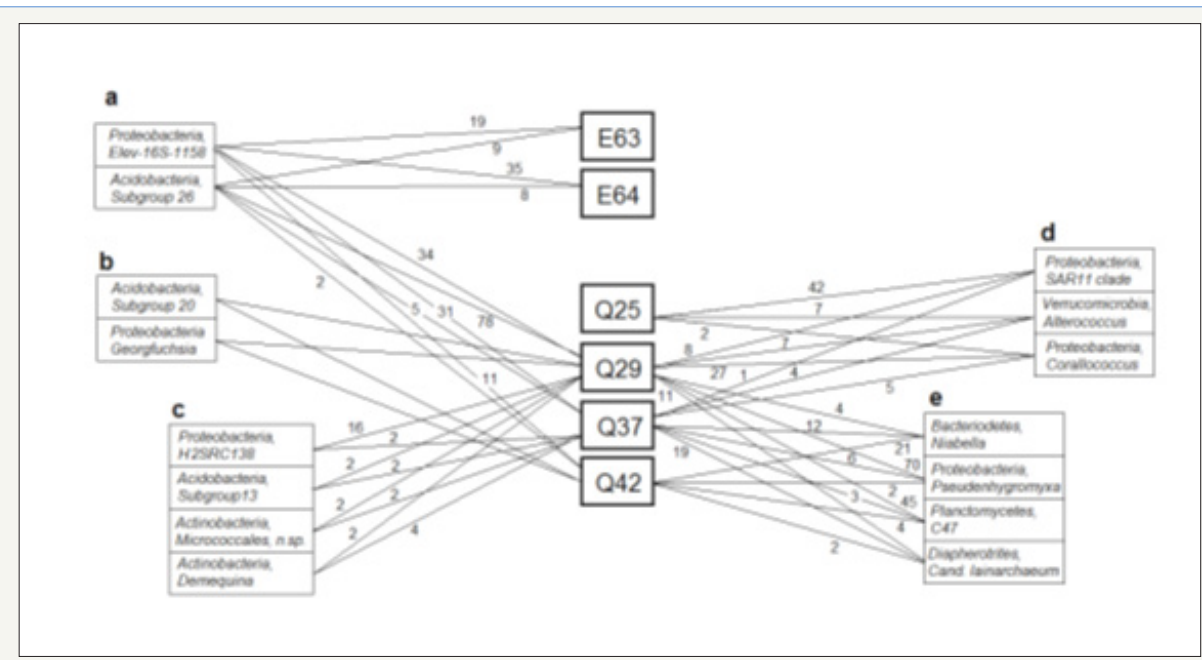

Figure 8: Five examples for detected exclusive associations: All shown OTUs are exclusively found in the marked group of soil samples, each association group was found at least in two different soil samples. The digits give the number of sequences representing the OTU in the related soil sample.

On the one hand is remarkable that despite the fact, that the samples are originating from surface material of several hundred years old mines, a high percentage of groups with halophilic character and taxonomic units are present, which are described from marine environments. This fact is evident for the above described associations, in particular. The character of these associations speaks for a long-term "genetic memory" of bacteria communities $[45,46]$ from these places. This observation fits to the fact that the ancient small mines are well recognizable in the landscape by their specific differences in surface morphology, soil structure and reduced, completely missing or special local vegetation. The reflection of significant differences between the single places by the existence or absence of certain soil bacterial associations on the one hand and the finding of a lot of exclusively provable single components on the other hand give strong advices to regard these small ancient mines as a valuable reservoir and source for new and unknown microorganisms with special tolerance features and potential specific metabolic capabilities.

\section{Conclusion}

The 16S-RNA NGS profilings of 17 ancient copper mines of the Southeast Harz region supply a differentiated picture of the dominant phyla and the rare operational taxonomic units (OTUs). The quantitative distribution of six dominant phyla (Plantomycetes, Actinobacteria, Proteobacteria, Gemmatimonadetes, Chloroflexi and Firmicutes) is comparatively strong correlated as the Principle Component Analysis (PCA) suggests. Acidobacteria and Bacteriodetes are related to each other, but more distinct from the first mentioned group. The phylum Verrucomicrobia shows the weakest relation to the other frequent phyla in the PCA. By analysis of the most frequent phyla, the soil samples can be subdivided into three groups, which are mainly distinguished by the percentages of Proteo- and Actinobacteria on the one side and Bacteriodetes, Verrucomicrobia, Planctomycetes and Acidobacteria, on the other side.

Despite the quantitative distinction by phyla, there was found that the samples from the single mines are marked by a set of rare types. Each sample supplied OTUs which had been exclusively assigned at one place. Other OTUs are present in several places. Among them, some groups had been identified which are found exclusively together in a few samples. Obviously, these groups represent sample-characteristic associations of rare microorganisms.

The results speak for the fact that the places of ancient mines reflect a certain ecological memory in the composition of soil bacterial communities. These comunities have to be regarded as a characteristic pool of rare and partially up to now uncultivated organisms. These specific communities should be protected and recognized as a potential source for future biotechnical requirements.

\section{References}

1. Schmidt A, Haferburg G, Sineriz M, Merten D, Buchel G, et al. (2005) Heavy metal resistance mechanisms in actinobacteria for survival in AMD contaminated soils. Chemie der Erde-Geochemistry 65(1): 131144 .

2. Liao M, Xie M (2007) Effect of heavy metals on substrate utilization pattern, biomass, and activity of microbial communities in a reclaimed mining wasteland of red soil area. Ecotox Environ Safety 66(2): 217-223.

3. Haferburg G, Kothe E (2010) Metallomics: Lessons for metalliferous soil remediation. Appl Microbiol Biotechnol 87(4): 1271-1280.

4. Li YY, Chen LQ Wen HY, Zhou TY, Zhang, et al. (2014) 454 Pyrosequencing analysis of bacterial diversity revealed by a comparative study of soils from mining subsidence and reclamation areas. J Microbiol Biotechnol 24(3): 313-323. 
5. Roane TM, Kellogg ST (1996) Characterization of bacterial communities in heavy metal contaminated soils. Can J Microbiol 42(6): 593-603.

6. Kaplon MA, Bloem J, Römkens PF, Ruiter PC (2005) Functional stability of microbial communities in contaminated soils. OIKOS 15(2): 119-129.

7. Niklinska M, Chodak M, Laskowski R (2006) Pollution-induced community tolerance of microorganisms from forest soil organic layers polluted with Zn or Cu. Appl Soil Ecol 32(3): 265-272.

8. Fierer N, Bradford MA, Jackson RB (2007) Toward an ecological classification of soil bacteria. Ecology 88(6): 1354-1364.

9. Torsvik V, Sorheim R, Gokskoyr J (1996) Total bacterial diversity in soil and sediment-a review. J Indust Microbiol 17(3-4): 170-178.

10. Daniel R (2004) The soil metagenome-a rich source for the discovery of novel natural products. Curr Opin Biotechnol 15(3): 199-204.

11. Lewis K, Epstein S, Onofrio D, Ling LL (2010) Uncultured microorganisms as a source of secondary metabolites. J Antibiotics 63(8): 468-476.

12. Silver S (1996) Bacterial resistances to toxic metal ions a review. Gene 179(1): 9-19.

13. Garcia JD, Sanchez R, Moreno R (2016) Bio-recovery of non-essential heavy metals by intra- and extracellular mechanisms in free living microorganisms. Biotechnology Adv 34(5): 859-873

14. Lewis K (2013) Platforms for antibiotic discovery. Nature Rev Drug Discovery 12(5): 371-387.

15. Hedrich, S, Schippers A (2017) Metallgewinnung mittels Geobiotechnologie. Chemie Ingenieur Technik 89(1-2): 29-39.

16. Bartelt J, Joshi J, Schmid B, Brandl, Hand T, et al. (2005) Soil feedbacks of plant diversity on soil microbial communities and subsequent plant growth. Persp Plant Evol Evol Syst 7(1): 27-49.

17. Margesin R, Siles JA, Cajthaml T, Ohlinger B, Kistler E (2017) Microbiology meets archaeology: soil microbial communities reveal different human activities at archaic monte Iato (Sixth century BC). Microbial Ecol 73(5): 925-938.

18. Reis MP, Barosa FA, Chartone E, Nascimento AM (2013) The prokaryotic community of a historically mining-impacted tropical stream sediment is a diverse as that from a pristine stream sediment. Extremophiles 17(2): 301-309.

19. Cornforth DM, Foste KR (2013) Competition sensing: the social side of bacterial stress responses. Nature Rev Microbiol 11(4): 285-293.

20. Crawford JW, Harris JA, Ritz K, Young IM (2005) Towards an evolutionary ecology of life in soil. Trends in Ecol \& Evol 20(2): 81-87.

21. Kürsten D, Möller F, Gross GA, Lenk C, Visaveliya N (2015) Identification of response classes from heavy metal-tolerant soil microbial communities by highly resolved concentration-dependent screenings in a microfluidic system. Methods in Ecology and Evolution 6(5): 600-609.

22. Cao J, Hafermann L, Köhler JM (2017) Stochastically reduced communities-microfluidic compartments as model and investigation tool for soil microorganism growth in structured spaces. Eng Life Sci 17(7): 792-800.

23. Clement M (1996) Tausend Jahre Metallerzbergbau in Mitteleuropa, VGE, Essen.

24. Quast C, Pruesse E, Yilmaz P, Gerken J, Schweer T, et al. (2013) The SILVA ribosomal RNA gene database project: improved data processing and web-based tools. Nucleic Acids Res 41: D590-D596.

25. Yilmaz P, Parfrey LW, Yarza P, Gerken J, Pruesse E, et al. (2014) The SILVA and All-species Living Tree Project (LTP) taxonomic frameworks. Nucleic Acids Res 42: D643-D648.

26. Klindworth A, Pruesse E, Schweer T, Peplies J, Quast C, et al. (2013) Evaluation of general $16 \mathrm{~S}$ ribosomal RNA gene PCR primers for classical and next-generation sequencing-based diversity studies. Nucleic Acids Res. 41(1): e1.
27. Hill CJ, Walsk KA, Harris JA, Moffet BF (2003) Using ecological diversity measures with bacterial communities. FEMS Microbiol Ecol 43(1): 1-11.

28. Berberán A, Velazquez C, Jones S, Fierer N (2017) Hiding in plain sights: Mining bacterial species records for phenotypic trait information. mSphere 2: e00237-17.

29. Thavamani P, Samkumar RA, Sathees V (2017) Microbes from mined sites: Harnessing their potential for reclamation of derelicted mine sites. Environ Pollution 230: 495-505.

30. Hong C, Si YX, Li Y (2015) Illumina MiSeq sequencing investigation on the contrasting soil bacterial community structures in different iron mining areas. Environ Sci Poll Res 22(14): 10788-10799.

31. Golebiewski M, Sikora E, Cichosz M, Tretyn A, Wrobel B (2014) 16 S rDNA pyrosequencing analysis of bacterial community in heavy metal polluted soils. Microbial Ecology 67(3): 635-647.

32. Shi PL, Zhang YX, Hu ZQ Ma K, Wang H, et al. (2017) The response of soil bacterial communities to mining subsidence in the west China Aeolian sand area. Appl Soil Ecol 121: 1-10.

33. Xie XH, Fu J, Wang HP, Liu JS (2010) Heavy metal resistance by two bacteria strains isolated from a copper mine tailing in China. African J Biotechnol 9: 4056-4066.

34. Feng GD, Yang SZ, Xiong X, Li HP, Zhu HH (2016) Sphingomonas metalli sp nov, isolated from an abandoned lead-zinc mine. Int J Syst Evol Microbiol 66(5): 2046-1051.

35. Barns SM, Cain EC, Sommerville L, Kuske CR (2007) Acidobacteria phylum sequences in uranium-contaminated subsurface sediments greatly expand the known diversity within the phylum. Appl Environ Microbiol 73(9): 3113-3116.

36. Weelink SA, Doesburg, Saia FT (2009) A strictly anaerobic betaproteobacterium Georgfuchsia toluolica gen nov, sp Nov degrades aromatic compounds with $\mathrm{Fe} / \mathrm{II}$ ), Mn (IV) or nitrate as an electron acceptor. FEMS Microbiol Ecol 70: 575-585

37. Wu ZH, Jiang DM, Li P, Li YZ (2005) Exploring the diversity of myxobacteria in a soil niche by myxobacteria-specific primers and probes. Environ Microbiol 7(10): 1602-1610.

38. Giovannoni SJ, Tripp HJ, Givan S, Podar M, Vergin KL, et al. (2005) Genome streamlining in a cosmopolitan oceanic bacterium. Science 309: $1242-1245$

39. Shieh WY, Jean WD (1998) Alterococcus agrarolyticus, gen nov., Sp nov., a halophilic thermophilic bacterium capable of agar degradation. Canadian J Microbiol 44: 637-645.

40. Kim BY, Weon HY, Yoo SH, Hong SB, Kwon SW, et al. (2007) Niabella aurantiaca gen. nov., sp nov., isolated from a greenhouse soil in Korea. Int J Syst Evol Microbiol 57(3): 538-541.

41. Youssef NH, Rinke C, Stepanauskas R, Farag I, Woyke T, et al. (2015) Insights into metabolism, lifestyle and putative evolutionary history of the novel archael phylum 'Diapherotrites'. ISME Journal 9(2): 447-460.

42. Iizuka T, Jojima Y, Hayakawa A, Fujii T, Yamanaka S, et al. (2013) Pseudenhygromyxa alsuginis gen. nov., sp. Nov., a myxobacterium isolated from an estuarian marsh. Int J Syst Evol Microbiol 63(4): 13601369.

43. Park S, Jung YT, Won SM, Yoon JH (2016) Demequina litorisediminis sp nov., isolated from a tidal flat, and emended description of the genus Demequina. Int J Syst Evol Microbiol 66(10): 4197-4203.

44. Jones SE, Lennon JT (2010) Dormancy contributes to the maintenance of microbial diversity. PNAS 107(13): 5881-5886.

45. Aanderud ZT, Jones SE, Fierer N, Lennon JT (2015) Resuscitation of the rare biosphere contributes to pulses of ecosystem activity. Frontiers in Microbiology 6: 24

46. Haferburg G, Kothe E (2007) Microbes and metals: interactions in the environment. J Basic Microbiol 47(6): 453-467. 
Creative Commons Attribution 4.0 International License

For possible submissions Click Here

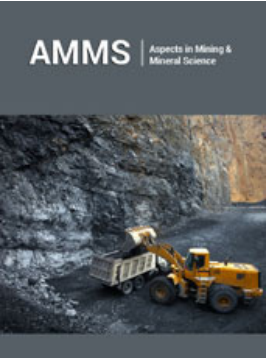

\section{Aspects in Mining \& Mineral Science}

\section{Benefits of Publishing with us}

- High-level peer review and editorial services

- Freely accessible online immediately upon publication

- Authors retain the copyright to their work

- Licensing it under a Creative Commons license

- Visibility through different online platforms 